\title{
Caffeine Consumption and Atrial Fibrillation: A Risk Assessment
}

\author{
Tomoyuki Kawada \\ Department of Hygiene and Public Health, Nippon Medical School, Tokyo, Japan
}

Dear Editor,

Abdelfattah et al. [1] conducted a metaanalysis and a dose-response analysis to evaluate the relationship between caffeine consumption and the incidence of atrial fibrillation (AF). Although the incidence of AF did not significantly increase by coffee consumption, a lower incidence of $\mathrm{AF}$ was observed in subjects with caffeine consumption exceeding $436 \mathrm{mg}$ /day [1]. I have a query on this study.

Caldeira et al. [2] evaluated the association between chronic exposure to caffeine and AF by a meta-analysis. The odds ratio (95\% confidence interval) of lowdose caffeine for AF was 0.85 (range 0.780.92 ), and relatively higher caffeine exposure showed no significant risk for AF. Cheng et al. [3] also conducted a metaanalysis to evaluate the association between chronic exposure of caffeine and the risk of AF. The relative risk (95\% confidence interval) of low-dose caffeine for incident AF was 0.89 (range 0.80-0.99). In addition, the relative risk of high-dose caf- feine for incident AF was 0.84 (range $0.75-0.94$ ), and there was an inverse doseresponse relationship between the amount of habitual caffeine intake and incident AF. Contrary to the results by Abdelfattah et al. [1], there would be a preventive effect of caffeine intake for AF, although the amount of exposure should be confirmed by further studies.

Recently, a systematic review without meta-analysis concluded that regular intake of caffeine up to $300 \mathrm{mg}$ /day would be safe or protective against atrial and ventricular arrhythmias [4], which was partly in concordance with the data found by Abdelfattah et al. [1]. There are many risk factors for AF, and continuous studies are required with special emphasis on lifestyle factors $[5,6]$.

\section{Disclosure Statement} est.

\section{References}

1 Abdelfattah R, Kamran H, Lazar J, Kassotis J. Does caffeine consumption increase the risk of new-onset atrial fibrillation? Cardiology. 2018;140(2):106-14.

2 Caldeira D, Martins C, Alves LB, Pereira H, Ferreira JJ, Costa J. Caffeine does not increase the risk of atrial fibrillation: a systematic review and meta-analysis of observational studies. Heart. 2013 Oct;99(19):1383-9.

3 Cheng M, Hu Z, Lu X, Huang J, Gu D. Caffeine intake and atrial fibrillation incidence: dose response meta-analysis of prospective cohort studies. Can J Cardiol. 2014 Apr;30(4): 448-54.

4 Voskoboinik A, Kalman JM, Kistler PM. Caffeine and Arrhythmias: Time to Grind the Data. JACC Clin Electrophysiol. 2018 Apr; 4(4):425-32.

5 Lau DH, Nattel S, Kalman JM, Sanders P. Modifiable risk factors and atrial fibrillation. Circulation. 2017 Aug;136(6):583-96.

6 Nalliah CJ, Sanders P, Kalman JM. The impact of diet and lifestyle on atrial fibrillation. Curr Cardiol Rep. 2018 Oct;20(12):137.

\section{KARGER}

(c) 2019 S. Karger AG, Basel

E-Mail karger@karger.com

www.karger.com/crd
Tomoyuki Kawada, MD

Department of Hygiene and Public Health, Nippon Medical School 1-1-5 Sendagi

Bunkyo-Ku, Tokyo 113-8602 (Japan)

E-Mail kawada@nms.ac.jp 